\title{
FOR THE USE OF SOUND. FILM SOUND ANALYSIS FOR AUDIO-DESCRIPTION: SOME KEY ISSUES ${ }^{1}$
}

\author{
Aline Remael \\ Artesis University College (Belgium) \\ Aline.remael@artesis.be
}

\begin{abstract}
This article aims to outline the issues involved in the production and reception of film sound with a view to identifying its challenges for audio-description (AD). It thereby hopes to provide insights into the way in which a careful analysis and integration of film sound and sound effects are required for the production of coherence in AD, if it is to function as part of a new filmic text. However, the article also points to the limits of analysis and interpretation, and to the need for reception research as well as collaboration with visually impaired users. A detailed analysis of a scene from Saving Private Ryan (Spielberg 1998), a film that won an Oscar for best sound effect editing, demonstrates how complex and narratively charged the soundscape of a film can be, thereby exposing the challenges for the audio-describer and, again, demonstrating the need for further research involving the target audience.
\end{abstract}

\section{Résumé}

Cet article concerne la production et la réception de la bande sonore et cherche à dégager quelques défis dans le domaine de l'audiodescription (AD). Il vise à démontrer comment une analyse et une intégration minutieuses de la bande et des effets sonores peuvent contribuer à la cohérence dans l'AD qui doit les incorporer pour créer une nouvelle version cinématographique. Il convient cependant également de souligner les limites de telles analyses et explications. Une étude de la réception ainsi que l'apport de malvoyants viendront avantageusement compléter les méthodes proposées.

1. Part of this article is based on a lecture given in June 2007, part of it has been funded by the European Project AD LAB: Audio-description. Lifelong Access for the Blind with reference no. 517992-LLP-1-2011-1-IT-ERASMUS-ECUE. 
Une analyse détaillée d'une scène de Il faut sauver le soldat Ryan (Saving Private Ryan, Spielberg 1998), qui a obtenu l'Oscar du meilleur mixage, mettra en évidence la complexité et l'importance narrative du paysage sonore d'un film et dégagera les défis des audiodescripteurs et la nécessité de recherches ultérieures prenant en compte le public cible.

Keywords: Audio-description. Sound effect. Narrative. Sound-image interaction. Reception research.

Mots clef: Audio-description. Effet sonore. Narration. Interaction son-image. Étude de la réception.

Manuscript received on July 7, 2011; Definitely accepted on November 15, 2011. 


\section{Introduction}

Film is an audiovisual medium that combines complex interactive systems of visual and aural signs to communicate a message, to tell a story. In the case of fiction film, the main concern of this article, viewers construct a narrative on the basis of the visual and aural clues that a given film puts at their disposal. However, since all viewers draw on their own backgrounds (as people, film viewers, members of different social groups and cultures etc.) they all see a slightly or considerably different film. In this respect, the experience of visually impaired audiences, which are as diverse as sighted audiences, is quite similar: they construct a personal variant of the film they are 'watching', a variant that will differ from but also be comparable to the versions experienced by other people with a visual impairment, and by sighted audiences. ${ }^{2}$

In view of this, cognitive mental modelling approaches to meaning construction offer a useful theoretical framework for understanding how film viewing works, i.e., how the members of a cinema audience construct a story (e.g., Branigan 1992) and how audio-description (AD) can help a blind audience construct a comparable story (e.g., Braun 2007). Building on this premise, it would seem that some of the core issues that the writers of AD scripts must resolve and that, indeed, feature prominently in all existing AD guidelines (Vercauteren 2007) are: determining which cues the film offers, when and how, and, which ones are not accessible to the AD audience.

It is the combination of the active participation required by film viewing and the combined 'audio'-'visual' nature of film that makes AD possible. By identifying the crucial strands of meaning that remain accessible and by filling in the gaps, AD creates a new meaningful story that allows its own varied audience to understand and enjoy the film, and remains close enough to the versions that sighted audiences construct. It is, indeed, important for the visually impaired audience to also benefit from the social functions of $\mathrm{AD}$

2. I am well aware that the target audience of AD is very diverse and comprises blind people as well as people who suffer from different forms and degrees of visual impairment. In what follows, the term visually impaired (audience) will be used to refer to the entire group of blind and partially sighted people. 
(e.g., providing points of convergence between the worlds of sighted and nonsighted people). Given the above, the first question AD scriptwriters must tackle is: where are the gaps? And this almost automatically leads them to focus on visually conveyed information. Definitions of AD usually run along the following lines,

[A] udio description (AD) is a precise and succinct aural translation of the visual aspects of a live or filmed performance, exhibition or sporting event for the benefit of visually impaired people (Hyks 2005: 6).

In addition, $\mathrm{AD}$ guidelines emphasise that

Descriptions are usually delivered during pauses or quiet moments. It is permissible to let pauses or quiet moments pass without a description. Conversely, since it is more important to make a production understandable than to preserve every detail of the original soundtrack, it is permissible to describe over dialogue and other audio when necessary (http://www.skillsforaccess.org.uk/howto.php?id=104).

At first sight, it seems logical that AD should focus on rendering visual information accessible and that this type of information should be given priority over elements of the sound track. However, AD-guidelines may be suffering from a bias that film studies is in the process of shedding, namely that film is a visual medium, aided by sound (section 2). The present article therefore aims to sketch the issues involved in the production and reception of film sound with a view to highlighting its importance and identifying some of its challenges for audio-description. It also shows (section 6.3) the difficulties involved in trying to identify where the limits lie of what can be reconstructed by a visually impaired audience on the basis of sound, and what cannot, with an analysis of a particularly complex scene in terms of sound design from Saving Private Ryan (Spielberg 1998).

\section{Sound and vision - functional and material complexities}

Few would be as radical as sound designer Randy Thom and state: "My opinion is that film is definitely not a visual medium" (1999: 4), but in film studies and practice alike the contribution of sound to film and its interaction with the medium's other sign systems, is being taken very seriously today (Jordan 2007, Barsam 2007: 273-314). The addition of sound is no longer considered to be an afterthought in film production, indeed, its role in cinematic meaning construction continues to grow, sound is considered to be integral to understanding the images or, in other words, sound shapes the picture sometimes as much as the picture shapes sound (Thom 1999: 1). 
This is also why Chion (1990: 61) writes: "il n'y a pas de bande son" (the sound track does not exist). Moreover, sound technology is possibly the fastest-evolving domain within cinematography today and this too is affecting the way sound functions in film, as well as the way in which the entire filmic sign system addresses the audience. As Thom writes:

It is even a little misleading to say 'a role sound plays' because in fact when a scene is really clicking, the visual and aural elements are working together so well that it is nearly impossible to distinguish them. (1999: 4)

Both film scholars and technicians specializing in sound therefore have their work cut out for them, analysing, improving and controlling the complex narrative functioning of sound, as well as the influence of material factors on its production. Altman (1992) stresses that (sound) events that are thought of as a single sound (e.g., a violin playing), are not singular at all. Distinguishing 'sound' and 'sound event', he points out that the production of any sound is a material occurrence that takes place in space and time, and involves the disruption of surrounding matter. Consequently, every sound event is composed of more than one sound, indeed, it

includes multiple sounds, each with its particular fundamental array of partials, each with its characteristic sound envelope, each possessing its own rhythm within the sound event's overall temporal range. (Altman 1992: 19)

What is more, for a sound to function, it must be heard and

By offering itself up to be heard, every sound event loses its autonomy, surrendering the power and meaning of its own structure to the various contexts in which it might be heard. (Altman 1992: 19)

As Altman points out, the concept of a sound 'event' introduces both a temporal dimension and spatial factors into the production and perception of sound. A sound will be different when heard from a distance or from another room, but as listeners we disregard certain aspects of sound events, while allowing others to play in our interpretation of what we hear. Using a term coined by Metz, Altman (ibid.) writes that the sound will be different but the "name of the sound" will be the same (it still is the neighbour's lawnmower that we are hearing, for instance) However, we may need visual or contextual information to figure this out.

All these aspects of sound are used in film, but also pose complex challenges for film production, and - one might add - film reception for a visually impaired audience. Today, film sound is 'constructed' during the post-production phase of filming as much or more than it is 'recorded' during production (Barsam 2007: 275). In Altman's terms (1992: 29), what recorded sound does is to 
represent(s) sound events rather than to reproduce them, recorded sound creates an illusion of presence while constituting a new version of the sound events that actually transpired.

To return to $\mathrm{AD}$, and considering its 'material' side, i.e., that of its representational quality, it would seem that, again, current AD practice underestimates the importance of sound, more specifically, the importance of quality recording. Blind test audiences regularly complain about the intelligibility of AD on DVD's. ${ }^{3}$ The problems they encounter in understanding the AD are related to the loudness and complexity of the aural channel of some films (cf. the increased prominence of sound in film discussed above), but also the poor mixing of $\mathrm{AD}$ into the sound track. In fact, a Dutch study into AD recording practices in the U.K., the European AD market leader (van der Heijden 2007), showed that these sometimes leave much to be desired. Having observed recording practices at ITFC and RedBee, van der Heijden concludes that the audio-describers often record their own text, but have little or no knowledge of sound and recording techniques. Men and women with very different voice qualities therefore tend to use the standard set-up of the recording equipment provided by the scripting software, whereas the equipment does allow users to adapt it. This can obviously result in poor recording quality (van der Heijden 2007: 17), and insufficient control over the undesirable 'material' sides of sound production. All the same, blind people are always expected to make the most of what they hear.

\section{Hearing and interpreting sound events, listening to a film}

An informative Flemish booklet, published by a local blind association and meant to promote understanding of blindness, states that

In their daily lives, people with a visual handicap use all their senses in their relations with the world. They can hear it when a car drives alongside the pavement, when it stops at a traffic light or when it is far away. By means of a subtle form of echolocation they hear the difference between covered and open spaces. (Infomap Volwassenen 2007: 38, my translation)

It is generally accepted that blind people do not necessarily have better hearing than sighted people, but that they have developed and trained their hearing in order to compensate for their lack of access to visual information. They are supposedly better at determining the place of origin and source of sounds,

3. This also happened during the discussion following my talk on film sound at the symposium "Audio-description for visually impaired people", held at the University of Surrey at Guildford on 28-29 June 2007. 
the distance of the source, the influence of material factors of a sound (revealing information about the environment) and even determining personality on the basis of a person's voice (van der Heijden 2007: 10). On the other hand, Seiffert (2005: 67) starts her article on "Räumliches horen", i.e. the way sound can convey information about the space in which it is produced, with a quote (taken from Hull 1992) rendering the way one blind person makes sense of his/her environment, showing the limits of aural compensation. The author claims that only actions produce sounds, whereas static environments do not (and must therefore be included in AD). This, however, is only partially true since some information about a room can be derived indirectly from the way sound (events) produced by a given source reverberate in space (cf. the concept of 'echolocation' above). On the other hand, the degree of recognition achieved will remain limited and will be conditioned by the functioning of the sound effects in the case of film (cf. infra). What is more, how and to what extent blind people can identify and interpret sounds will also be determined by personal factors that will vary from one listener to the next. In short, we can assume, basing ourselves on accepted opinion and the varying testimonies of blind people, that their hearing is developed through training, but that the extent to which it is heightened is difficult to ascertain, especially in general terms. (Infomap Volwassenen 2007)

The lessons to be learnt for film viewing and $A D$ are therefore far from straightforward. They are determined by the complexities of sound production and reception generally, by what the specific target audience can or cannot handle, and by the way film uses sound. In brief, it is important for film sound to be fully available for the blind audience and for the interaction between aural and visual film narration to be enhanced, exploited to the full. However, which sounds the audience will or will not be able to distinguish and interpret cannot always be taken for granted because of the various production and reception issues, mentioned above, but also because film sound is a narratively motivated representation that merely poses as realistic sound and that is 'realistic' only within the context of some film genres.

\section{Film sound and film narrative}

The realization that film sound is anything but reproductive and has surpassed the era of indexicality, i.e., that there is not a straightforward relationship between a given film sound and a sound that exists in a pre-production environment, is central to understanding how film sound functions. Consequently, it is also central to understanding how this functioning can contribute to improving its integration into $\mathrm{AD}$. On the one hand, a blind person 
may be trained in identifying sounds and therefore should be given the opportunity to put this skill to good use when watching a film; on the other hand, not necessarily being realistic, film sounds can be difficult to place for an audience without access to the images they complement. Finally, locating the source of a sound does not guarantee access to the function the sound fulfils in the narrative.

Recent research has shown that it is a fallacy to believe that AD can recreate ' $a$ ' film, that it can be objective, and that it suffices for describers to "describe what they see" (see Díaz-Cintas et al. 2007, Fix 2005, Jiménez Hurtado 2007, Remael \& Neves 2007). AD should allow its blind audience to understand and enjoy films, while offering them inroads into the visual world around them - which implies that when they have 'watched' a film, their interpretation and appreciation of the movie should be within the sighted audience's range of interpretation and appreciation (cf. above). The film signs from which the experience is constructed cannot and need not function in the same way for both audiences.

When considering film sound and visuals from this perspective, they can be handled quite creatively by the describer. If the "referent of Hollywood sound is not the pro-filmic scene at all, but a narrative constructed as it were 'behind' that scene [...]" (Altman 1992: 59), this means that its functioning varies with each production (and scene), but is also determined by genre. When a film leans towards the poetic rather than the narrative, for instance, both its visual and aural signs will function quite differently. Moreover, sound can both complement and detract from the visuals on screen, meaning it is up to the describer to determine its function, relevance and usefulness for the (re)creation of a film story in each particular instance.

Some of the main tasks that the sound track can take on are (Thom 1992: 9):

- suggest a mood, evoke a feeling

- set a pace

- indicate a geographical locale

- indicate a historical period

- clarify the plot

- define character

- connect otherwise unconnected ideas, characters, places, images, or moments

- heighten realism or diminish it

- heighten ambiguity or diminish it 
- draw attention to detail, or away from it

- indicate changes in time

- smooth otherwise abrupt changes between shots or scenes

- emphasize a transition for dramatic effect

- describe an acoustic space

- startle or soothe

- exaggerate action or mediate it

Moreover, Thom writes (ibid.), sound is likely to be doing several of these things at once. Still, the sound track consists of music, dialogue, and sound effects, each of which have their own features and 'specialties', so to speak. The subsequent sections of this article will focus on some of the peculiarities of sound effects and the challenges they may present for $\mathrm{AD}$.

\section{Sound effects within the bigger picture}

One dictionary definition of 'sound effect' reads: "a sound other than speech or music made artificially for use in a play, film, or other broadcast production" (New Oxford Dictionary 1998). The crucial words in this definition, from the point of view of $\mathrm{AD}$, are "made artificially". The extent to which the artificial source of the sound will turn out to be problematic for a blind audience - or not - is of course directly linked to how this source is embedded in the filmic sign system as a whole.

Turner (2005) distinguishes three different types of effects: impact, Foley and ambience effects. Impact effects are created either for a diegetic inanimate object that has no aural identification in the 'real' world, or for an object that needs emotive impact within the diegesis (e.g., car tyres screeching). Foley effects, named after pioneer Jack Foley, involve artists who synchronize the actions of a character projected on a screen and record the relevant sound in a 'sound pit', which usually has ground platforms of different materials (e.g., footsteps, opening and closing of doors). Ambience effects aim to recreate the sound of specific locations (e.g., the echo of a cave, but also the roar of a crowd in a stadium).

Since even sounds generated to increase realism, are usually created artificially, this raises questions about how recognizable they are independently of the images. Moreover, the distinction between sound effects and music, for instance, is often blurred, which supposedly places an even heavier burden on the capacities of blind audiences to interpret what they hear. Classic examples of such mixing of sound types occur in Hitchcock classics such as The Birds (1963) in which avian noises imitate the functions of music, or Psycho (1960) 
in which music (screeching violins) imitates both birds and the screams of Marion Crane (Janet Leigh), as she is assassinated in the shower. An added difficulty may be the distinction between diegetic and non-diegetic noises (or sound effects). The source(s) of the latter may be less easily identifiable and may require more support from the $\mathrm{AD}$ ) (see 6.3).

Film narration will usually come to the rescue as long as a diegetic noise can be associated with a source, i.e., with an action on or off screen, and on condition that there is time for this action to be described. What must then be restored is what Chion (1990: 55) calls "la synchrèse":

...la soudure irresistible et spontanée qui se produit entre un phenomène sonore et un phenomène visuel ponctuel lorsque ceux-ci tombent en même temps, cela indépendamment de toute logique rationelle. ${ }^{4}$

What is more, even if sound and image do not fully coincide (whether temporally, spatially or logically), the spectators (constructing their story) will experience them as synchronous. ${ }^{5}$ Our hypothesis is that for this effect to work in $\mathrm{AD}$, it must supply the visual information with which the sound must be linked, whenever this cannot be deduced from the sound itself (cf. 6.3)

According to Chion (1990: 25-32), we perceive sounds in three ways, but one of these, causal listening, is by far the most important one for the way we experience the world, and by extension, films. ${ }^{6}$ This way of listening uses a sound to identify its cause or source. Listeners do this on the basis of their knowledge of types of noises and their causes as much as on the basis of hearing (cf. 6.3). Moreover, they use contextual hearing: they may, for instance, know that the neighbours have a dog; or, in the case of film, that the main character has a dog. Sometimes listeners will only recognize a category, say, a radio presenter, without knowing what she looks like; or they hear a rhythm that repeats itself and punctuates events, and can recognize it as human versus mechanical, without knowing its exact source. Moreover, a noise can be identified by different sources working together, like a pencil making a scratching noise on paper versus chalk on a blackboard. The purpose of sound effects is often to make the audience believe that certain sounds are produced by certain sources, whereas they emanate from others.

4. ...the irresistible and spontaneous suture that is produced between an aural and visual phenomenon when these occur simultaneously, irrespective of logical connections. (My translation)

5. The dubbing of foreign language productions also relies on this effect.

6. Causal listening (see main text), semantic listening (which uses a code or language to produce meaning) and reduced listening (which takes a sound as its object of observation). 
This may lead to problems for blind audiences when the cinematic source that the sound is meant to represent is difficult to identify without the help of visual input. The next section considers a few examples that involve lack of synchrony, point of view sound (or subjective sound as experienced by a character), multiple and/or diffuse sounds.

\section{Challenging sounds: a few examples}

\subsection{Lack of synchrony and point of view sound}

Not all instances with asynchronous sound are necessarily problematic. In The Hours (Daldry 2002), Leonard Woolf (Steven Dillane) is seen walking home with his dog early on in the film, and the ambient street noises are audible, but the dog does not make a sound. When man and dog reach the house, the dog runs towards the front door, ahead of Woolf, and starts to bark. The blind audience can place the sound because the AD anticipates it and tells its audience that Woolf is accompanied by his dog while they are still in the street. In fact, this sound is not fully asynchronous: when the dog barks it is also on screen, the animal has simply been introduced visually first, unknowingly to the visually impaired (or in this case, blind) audience. This is a gap that can easily be identified and filled.

In some instances, however, asynchronous sound will supply additional information almost independently; it can - for instance - be produced (and heard) simultaneously with images to which it does not refer, but build on a combination of this visually conveyed information and the active summoning of narrative logic in order to make sense. In one classic scene in Le Million (René Clair 1931), shots of characters scrambling to find their lottery tickets are accompanied by the extradiegetic sounds of a football game for comic effect. For such a scene to work, it may suffice to explain the visuals and to let the sounds of the football match interact with the description in much the same way as the sound would otherwise interact with the images. However, only reception research can confirm or falsify this hypothesis. In another classic, Robert Bresson's A Man Escaped (1956), a man held in a Nazi prison never sees the world beyond the prison walls again, but remains aware of it as he hears the sounds of church bells and trains 'out there'. The sound is asynchronous in the sense that the source of the sound is not part of the character's world. In this case, the AD would have to make sure the audience associates the sounds the character and they themselves hear, with the character's experience. The sounds introduce point of view into the story, a very common trick of the trade. The standard example of the use of such 
subjective intradiegetic sound is that of a noise growing dimmer when the distance between its source and the fictional character who hears the sound grows. In an AD aiming to allow the sound to fulfil its function, the character in question would probably have to figure as a reference point to explain the gradual fade.

\subsection{Multiple or diffuse sound and its functioning}

The presence of multiple sounds often results in an overall effect of diffuse sound since a multitude of different sounds coming from different sources may be difficult to distinguish from one another. However, multiple sounds too are more problematic in some cases than in others and can sometimes help a non-sighted audience construct a variant of the visual narrative that functions perfectly.

Seiffert (2005: 71ff) writes that when describing a particular space, audiodescription makes use of the listener's supposed mental images of that space. Blind audiences can be expected to know, for instance, what kind of furniture they might encounter in a space named 'office'. This knowledge can even allow the description to take the presence of some objects for granted and to refer to them with a definite article (e.g., 'the' desk) even the first time they are named. Cohesion is maintained thanks to the general mental image any viewer within a certain cultural context can be expected to have of an office. This mental modelling approach can also be applied to sound. A battle, for instance, is associated with certain noises, which means that the viewer/ hearer will usually be able to place them without requiring much description. What is more, if the viewers can be expected to have some historical knowledge of the battle, the landing on the heavily fortified beaches of Normandy in Saving Private Ryan (Spielberg 1998), for instance, the sound track alone may allow them to conjure up quite specific events (cf. section 6.3). Indeed, anyone about to watch a film on DVD or in the cinema will have consulted the programme and have some idea of what to expect. But then again, some (action) scenes may become too aurally complex or loud in some cases, and it will be up to the describer to decide which noises are traceable and which are not, with the help of a test audience. ${ }^{7}$

7. This can also occur in disaster films such as 2012 (Emmerich 2009), in which the world as we know it comes to an end. In order to maintain the suspense of disaster scenes, the AD will have to create some order in the cacophony of noises (Matamala \& Remael 2011; and work in progress). 
Very specific types of action scenes and fights, visually and aurally impressive ones, are those that are the staple of science fiction movies such as $V$ for Vendetta (MacTeigue 2005) or X-Men. The Last Stand (Ratner 2006), but also of poetic martial arts films such as Hero (Zhang Zimou 2004). In such films some fighting noises will still be recognizable, whereas others will refer to weapons from another time or place and the setting will probably be out of this world - again to a greater or lesser extent. Moreover, some images and complementary sounds may have a purely aesthetic function. Such sounds may then be especially difficult to trace to a source and even harder to place within the ongoing narrative including with the help of AD. In Hero many of the fights are like ballets of movements and sounds. Rendering all the movements and thereby identifying the sources and functions of all the sounds is quite impossible. What is more, in one particular instance, some of the objects of the temple in which a fight takes place also produce sounds that can be identified in themselves, but cannot be related to the fight. At one point, for instance, a drop of water falling from the roof of a building into a bucket is shown in close up. The event comes in between the shots of the fight, the sound is quite distinct and the image adds to the atmosphere and aesthetics of the scene. Again, there is no time to describe all this visual information. The English AD on the DVD of the film limits itself to rendering some of the movements of the fight, and selects some ambient noises in between. It actually summarizes the fight, ensuring that it thereby also explains the most audible sounds that the movements of the combatants produce, thereby creating a sort of 'order' in what might otherwise come across as a diffuse ensemble of noises, but leaving quite a bit to the imagination. The symphony of sounds replaces the symphony of sounds, movements, shapes and colours of the visual rendering, and the $\mathrm{AD}$ allows its target public to construct its own version of the scene within the ongoing narration, ensuring its narrative functions are covered.

\subsection{The case of Saving Private Ryan (Spielberg 1998)}

Among the many Oscars won by the Spielberg film Saving Private Ryan, were Best Effects and Best Sound Effect Editing. ${ }^{8}$ The 30 most famous minutes of the film are those including the landing of the allied forces on the beaches of Normandy in 1944. In these scenes, the spectator is meant to feel (s)he is physically present among the soldiers who are being blown to pieces by

8. The people responsible for these were Gary Rydstrom and Richard Hymns (http://www. imdb.com/title/tt0120815/awards) 
German enemy fire. This is conveyed visually by gruesome close-ups of wounded soldiers, by the chaos and desperation in the shallow water close to the beach, on the beach and beyond, but also by the sound track, which mixes the sound of the guns with the screams of the soldiers and other loud battle noises. The question for the $\mathrm{AD}$ is: how many noises need to be described and to what extent can the sources of the noises be identified, thereby making description unnecessary.

As I pointed out in Section 1, "viewers construct a narrative on the basis of the visual and aural clues that a given film puts at their disposal", and mainstream feature films are constructed to supply what is needed, moreover, effects are usually meant to enhance the narrative (McClean 2006) - but not for a visually impaired audience. In the analysis below, I try to identify which noises are identifiable on the basis of narrative context and in conjunction with other noises. The exercise proved to be quite complex, but it is one that any audio-describer would have to make. ${ }^{9}$ I start from the premise that the audience knows they are about to watch an American film about World War II that starts out with the landing of some of the allied forces on the coast of Normandy. The date is "June 6, 1944" and the place "Dog Green Sector, Omaha Beach". In fact, this text appears on screen and would be mentioned by any AD.

First, the sound of violent waves washing ashore is heard (and can be contextualized on the basis of the above text). The waves hit intricate rows of huge metal crosses that form part of the German defence lines (and these must be described, cf. infra). The sound of the sea changes and is combined with the metallic sound of a humming motor (identifiable: boats at sea; not identifiable: type of boat, this the AD must specify). To the above, a less distinct but audible metallic sound is added (a soldier in one of the boats drinks from a gourd, he wears a helmet: AD of both helmet and gourd are required, cf. infra). The repeated sound of vomiting is heard and is quite obvious (identifiable through the sound track and the narrative context of boats on a rough sea). The sound of the motor has now become more distinct and could be identified as that of a smallish boat (audience testing required, but it may be better to mention the type of boat when the vessel is first introduced). The instructions quoted below are then shouted. These further clarify the events

9. To my knowledge, there is no $\mathrm{AD}$ of the film available. The purpose of the second stage of this research is to write the $\mathrm{AD}$, record the scene again and test it on a visually impaired target audience. 
on screen: the boats are packed with soldiers about to land on Normandy's "Omaha" beach.

The soldier at the helm of one boat says:

"Clear the ramp! 30 seconds to landing. God be with you!"

A voice (Captain Miller/Tom Hanks, the character remains unnamed at this point) shouts:

"Port side, stick. Starboard side, stick. Move fast and clear those mortar holes."

In another boat, a second voice shouts:

"I want to see plenty of beach between men. Five men is an opportunity. One man is a waste of ammo."

First voice:

"Keep the sand out of your weapons. Keep those actions clear. I'll see you on the beach."

Miller's line, "I'll see you on the beach", is accompanied by the noise made by the waves hitting both the boats and the men in the boats (which can be seen, but may be hard to hear), then a whizzing sound follows (bullets, identifiable given the context), followed almost immediately by the sound of heavy explosions and more sounds of vomiting. The power of the enemy fire is obviously formidable, whereas the men in the boats are sick (and weak?) as they sail into the firing line. The mixture of sounds that follows next signals that the landing is approaching, but they are quite diffuse: cannon fire, mortar fire, coughing, the sound of the motor of the boat slowing down, more vomiting, a whistle blowing, the sound of the ramp opening, and orders being shouted simultaneously. These are accompanied by 'unheard' visually rendered actions that render the anxiety the soldiers must be feeling: one soldier is crossing himself and another kissing the cross on a chain round his neck. Are these actions essential, one might ask. The sound track alone would no doubt convey a general picture of the chaos of the landing, but the silent reactions of the men add to the personal drama of the scene, and these would go unnoticed without AD.

As the order "Open mortar holes" is shouted and the screeching noise of the ramp opening is heard, the noise of the shooting suddenly increases dramatically in volume. It is composed of a mixture of machine guns, the darker sound of cannons and the very prominent whizzing sound of bullets. Visuals and noise together show that the specific boats and their 'cargo' of soldiers that we have been following have come under fire, but this must be mentioned to confirm the meaning of the change in sounds. 
What is more, now and again, the boats are shown from the point of view of the German soldiers in their bunkers. In these shots the noise of the machine guns increases, but the link between this subtle change in sound and the change in point of view is probably impossible to make without visual support. And yet, the change in camera position is important, because it reveals the metal crosses on the beach again (in and close to the water). The German viewpoint and the defences on the beach must be described to allow the target audience to reconstruct their story. (cf. also infra).

Meanwhile, the whizzing sound stands out among the other firing sounds and is meant to be experienced as close by: it is as if the bullets could hit you, the viewer, any time. There is also the sound of bullets hitting metallic objects: the boats and/or the helmets of the soldiers, objects that have been mentioned earlier by the AD. Indeed, at this point, the noise is so deafening that it would be virtually impossible to shout a description over it, but if boats, soldiers, helmets, metal crosses and the beach landing are in place, the sounds can hopefully be left to do their job. On the other hand, one just about hears Miller's 'Over the side' - which in combination with what feels like an almost material "wall of noise" ought to explain the soldiers cannot get out of the boats at the front. Then again, due to the barrage of noise the voices of other men shouting orders ("Port and starboard, over...") barely get through. In other words, the instructions, telling the soldiers to jump overboard, which are clear in combination with the images, may well be lost, but soon enough, the splashing of water and the sound of heavy objects falling into the water are added to the previous noises. These sounds are again identifiable and tell the attentive listener that the soldiers are jumping or falling into the water - which, or that is my hypothesis, may have to be confirmed only briefly by the AD.

When the camera goes under water to film the action, the gunfire is muffled at once, and is replaced by a droning underwater sound, as well as the sound of air bubbles, movements, shuffling under water, and a softer whizzing sound, that of bullets piercing the surface of the sea. This continues for some time. The overall noise has quietened down and has become more diffuse. While it is clear that the action is now taking place under water, it becomes even harder to make out what exactly is happening. Maybe visually impaired audiences would be able to guess that some soldiers are seen struggling under water, however, what will be lost once again is the variety of ways in which they struggle and die (shot by bullets or drowning as they try to get out of their heavy gear). 
The continuous drone and the underwater noises are then punctuated by loud interruptions of splashing combined with the loud noise of gunfire. This is the result of the sound track and visuals alternating between sounds under water and above water, signalling the struggle of the soldiers trying to reach the beach. The visuals include a point of view shot of what a soldier struggling to leave the water sees, which - of course - remains unheard.

The sounds then remain above water: This signals a subsequent stage in the chronology of the landing, which may have to be confirmed by the AD. All the different types of gunfire from earlier on in the scene have returned and to this another sound is added, a clanging sound. It is the sound of the soldiers' weapons hitting the huge metal crosses laid out in rows on the beach, which would have been described by the AD earlier on. A brief repeat-mention of the crosses should be able to create cohesion with the earlier description and place this sound. On the other hand, all the noises together constitute an overwhelming cacophony of gunfire, shouting, waves rolling on to the beach and the continued clanging of metal against metal as the soldiers remain stuck between the metal crosses and cannot move on. It is not altogether clear whether visually impaired viewers would be able to determine what is happening; the aural picture that the deafening and varied battle noises paint remains less detailed than the visual-aural one. The occasional alternation between machine guns (bunker point of view) and clanging (soldiers' point of view) is very difficult to distinguish on the basis of sound alone, and the listeners keep missing the occasional focus on what happens to individual soldiers as they are killed and colouring the sea red. Captain Miller, for instance, has survived the landing and is moving between the bodies and men. As he tries to help one private get out of the water, and the soldier says 'Thank you', the latter is shot. The gunshot can be heard, but without the help of the $\mathrm{AD}$, its function is lost.

Then, rather abruptly, the cacophony of noises stops and intradiegetic sound is replaced by a monotonous, humming extradiegetic sound, one that cannot be linked to the ongoing action. The visuals switch to slow motion and focus on the agony of a number of individual soldiers as witnessed by Miller, i.e., from his point of view, as he is sitting on the beach close to the metal crosses. The combination of this quieter, eerie sound, and the slow motion butchery the audience witnesses from Miller's subjective point of view, convey (at least for this viewer) the feelings of helplessness and shock experienced by the commander as he watches his men being killed or maimed. One particularly harrowing picture is that of a soldier whose arm has been blown off. He picks it up and continues walking up the beach. 
Obviously, these personal stories complement the overall picture painted jointly by image and sound, but do not come across through sound alone. The sound track now only produces the eerie background sound, the images provide the narrative. The functions of image and sound appear to have been separated. AD is required, but must the eerie extradiegetic sound accompanying the slow motion be identified? Or can this be done indirectly through the description of what Miller sees? Since the sound track is now monotone and much quieter, it can be overruled to provide detailed description.

Adding some form of AD here is essential since this part of the landing scene has at least two functions: the cruelty of the war is personalized (we see individual soldiers suffering) and this has an impact on Miller, one of the protagonists. Indeed, as McClean (2006) writes, effects are used to enhance the narrative, and especially the bravery of protagonists, which is a driving force in Hollywood type causal narratives (Bordwell \& Thompson 2008): Since Hollywood movies are character-driven, the events that have an impact on Miller are bound to have an impact on the narrative as a whole. In other words, the way in which Miller witnesses and experiences the slaughter is as important as the slaughter itself. If some of the concrete events he witnesses are explained, from his point of view, our hypothesis is that this would automatically clarify the more symbolic function of the eerie sound track that focuses the sighted audiences' attention on Miller's feelings. The combination of extradiegetic sound and slow motion signals a shift from 'external' reality to 'internal' or subjective reality.

\section{Concluding remarks}

The first part of this article has demonstrated the importance of sound and sound design for film narration, discussed some of the complexities involved in the production, reception and interpretation of sound, and hence the importance of its integration in what we could call 'AD design', both at scripting and recording level.

The brief analysis of one visually and aurally complex film scene with distinct, diffuse, intradiegetic and extradiegetic sounds, has demonstrated what the challenges can be. The central question that remains is to what extent the film can be trusted to tell its own story and the audience given an active role in constructing 'their' story. The visual narrative definitely adds more dramatic detail to the story because it helps the sighted audience identify sounds -even if this guidance or interaction goes unnoticed- and, in addition, it sometimes contributes 'silent' visually conveyed information. This means that in some cases, the $\mathrm{AD}$ will have to identify the source of a sound, in others it 
will have to give narrative context, or even indicate the narrative function of a sound (cf. the example of extradiegetic sound). What is more, the exact relationship between sound and (subjective) point of view begs more questions than this article can resolve. The only solution seems to be: Testing scenes such as the one described above, and others, on visually impaired audiences, with a view to establishing if guidelines can be drawn up regarding the way these audiences use and/or can learn to use the sound track in conjunction with the other filmic systems to reconstruct 'their' story.

\section{References}

Altman, Rick (ed.) (1992) Sound Theory, Sound Practice. London: Routledge.

BARSAM, Richard. (2007) Looking at Movies. An Introduction to Film. New York: Norton.

BorDWELl, David \& Kristin Thompson. (2008) Film Art. An Introduction. Eighth Ed. Boston: McGraw Hill.

BRANIGAN, Edward. (1992) Narrative Comprehension and Film. London: Routledge. BRAUN, Sabine. (2007) "Audio description from a discourse perspective: a socially relevant framework for research and training". In: Remael, Aline \& Josélia Neves (eds.) 2007. A Tool for Social Integration? Audiovisual Translation from Different Angles. Theme issue. Linguistica Antverpiensia NS6. pp. 357-369.

CHION, Michel. (1990) L'Audio-vision. Paris: Nathan

DíAz CinTAS, Jorge; Pilar Orero \& Aline Remael (eds.) (2007) Media for All. Subtitling for the Deaf, Audio Description, and Sign Language. Amsterdam: Rodopi.

FIX, Ulla (ed.) (2005) Hörfilm. Bildkompensation durch Sprache. Berlin: Erich Schmidt Verlag.

HYKs, Veronika (2005) "Audio Description and Translation. Two related but different skills." Translating Today 4 (July 2005). pp. 6-8.

Infomap Volwassenen (2007). Didactisch materiaal (Didactic material). Gent: Blindenzorg Licht en Liefde.

JiMÉNEZ HuRTADO, Catalina (ed.) (2007) Traducción y accesibilidad. Subtitulación para sordos y audiodescriptción para ciegos: nuevas modalidades de Traducción Audiovisual. Frankfurt am Main: Peter Lang.

JorDAn, Randolph. (2007) "Sound in the Cinema and Beyond". Offscreen 11: 8-9 (Aug/Sept. 2007). pp. 1-16. Full text-version at: <http://www.offscreen.com/ biblio/pages/index/975/>. [Retreived on 16 April 2008].

MCClEAn, Shilo T. (2006) Digital Storytelling. Cambridge: MIT Press.

Remael, Aline \& Anna Matamala. (2011) "Audio-description revisited." Paper delivered at the international conference Points of View in Language and Culture, Jagiellonian University, Krakow, 14-15 October 2011. 
Remael, Aline \& Josélia Neves (eds.) (2007) A Tool for Social Integration? Audiovisual Translation from Different Angles. Theme issue. Linguistica Antverpiensia NS6.

SEIFFERT, Anja. (2005) "Räumliches hören. Eine schemaorientierte Analyse der audiodeskriptiven Darstellung der Handlungsräume”. In: Fix, Ulla (ed.) 2005. Hörfilm. Bildkompensation durch Sprache. Berlin: Erich Schmidt Verlag. pp.76-86.

THOM, Randy. (1999) "Designing A Movie For Sound." Online at FilmSound.org. Learning Space dedicated to the Art and Analyses of Film Sound Design. Full text-version at: <http://www.filmsound.org/articles/designing_for_sound. htm $>$. [Retrieved on 16 April 2008].

TURner, Ben. (2005) "Acoustic Ambience in Cinematography: An Exploration of the Descriptive and Emotive Impact of the Aural Environment." Submitted in partial fulfilment of the requirements for the degree of Master of Music in Composition, University of KwaZulu-Natal, Durban, September 2005. Full text-version at: <http://www.filmsound.org/articles/designing_for_sound. htm>. [Retrieved June 2007. PDF-version available from the author of this article].

VAN DER HEIJDEN, Mereijn. (2007) Film en televisie toegankelijk voor blinden en slechtzienden. Een onderzoek naar de functionaliteit van geluid bij audiodescriptie (Film and television accessible for the blind and partially sighted. A research into the functionality of sound in audio-description). MA-paper. Hogeschool voor de Kunsten Utrecht, Faculteit Kunst, Media \& Technologie.

VerCAuteren, Gert. (2007) "Towards a European guideline for audio description." In: Díaz-Cintas, Jorge; Pilar Orero \& Aline Remael (eds.) 2007. Media for All. Subtitling for the Deaf, Audio Description, and Sign Language. Amsterdam: Rodopi. pp. 139-149.

VV.AA. "Provide audio descriptions for video or animated content - general advice", Skills for Access. The comprehensive guide to creating accessible multimedia for e-learning. Full text-version at: <http://www.skillsforaccess.org.ik/ howto.php?id=104>. [Retrieved on 16 April 2008]. 


\section{BIONOTE / NOTA BIOGRÁFICA}

\section{Aline Remael}

Aline Remael (www.alineremael.be) is a professor of audiovisual translation and translation theory at the Department of Translators and Interpreters of Artesis University College, Antwerp. Her main research interest is in audiovisual translation (intralingual and interlingual subtitling, live subtitling and audio description). She has published widely on the subject, and she is the co-author of Audiovisual Translation: Subtitling (St Jerome, 2007) with Jorge Díaz-Cintas. She has also co-edited several volumes on audiovisual translation and media accessibility, among which Media for All 1. Subtitling for the Deaf, Audio Description and Sign Language (Rodopi, 2007), and Media for All 3. AVT and Media Accessibility at the Crossroads (Rodopi, forthcoming). She was the convenor of the Third International Media for All Conference, "Quality Made to Measure", held in Antwerp in October 2009 and of the $3^{\text {rd }}$ International Symposium on Life Subtitling with Respeaking, held in Antwerp in October 2011. At present, she is a partner in ADLAB (Audio-Description: Life-Long Learning for the Blind, 2011-2014), a three year project financed by the European Union under the Life Long Learning Programme. She is also a member of the TransMedia Research group, chair of the TransMedia Benelux Research Group and member of the advisory boards of The Translator, Perspectives: Studies in Translatology and the Peter Lang book series New Trends in Translation Studies. In addition, she is the chief editor of Linguistica Antverpiensia New Series, Themes in Translation Studies (www.lans-tts.be).

Aline Remael (www.alineremael.be) est chargée de cours au département des Traducteurs et Interprètes de la Artesis University College à Anvers, où elle enseigne les cours de traduction audiovisuelle et de théorie de la traduction. Ses sujets de recherches concernent essentiellement la traduction audiovisuelle, notamment le sous-titrage intralingual et interlingual, le sous-titrage en direct et l'audiodescription. Elle a de nombreuses publications internationales dans ces domaines. Ainsi, elle a écrit, avec Jorge Díaz-Cintas, Audiovisual Translation: Subtitling (St Jerome, 2007) et coédité différents volumes concernant la traduction audiovisuelle et l'accessibilité aux medias, dont Media for All 1. Subtitling for the Deaf, Audio Description and Sign Language (Rodopi, 2007) et Media for All 3. AVT and Media Accessibility at the Cross-

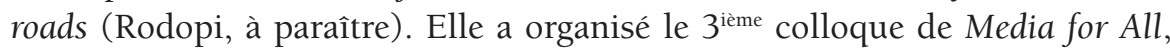
"Quality Made to measure", qui s'est tenu à Anvers en octobre 2009 ainsi que le $3^{\text {ième }}$ colloque international portant sur le sous-titrage en direct (Life Subtitling with Respeaking), également à Anvers en octobre 2011. Actuellement, elle 
fait partie de ADLAB (Audio-Description: Life-Long Learning for the Blind, 2011-2014), un projet de recherche de trois ans financé par l'Union Européenne dans le cadre du programme pour l'éducation et la formation tout au long de la vie. Elle est membre du groupe de recherche TransMedia et présidente de la section TransMedia Benelux. Elle fait partie des comités de rédaction de The Translator, de Perspectives: Studies in Translatology et de la collection New Trends in Translation Studies chez Peter Lang. Elle est rédacteur en chef de Linguistica Antverpiensia New Series, Themes in Translation Studies (www.lans-tts.be). 